\title{
LA PERONIZACIÓN DE UNIVERSITARIOS EN LOS AÑOS SESENTA Y SETENTA
}

Nicolás Dip (Coord.)*

Recibido: 26/05/2017 // Aceptado: 14/07/2017

\section{Introducción}

Un lugar común a la hora de pensar la relación entre peronismo y universidad es referirse a la importante oposición que concitaron los dos primeros gobiernos de Juan Domingo Perón en ese ámbito particular. Otro lugar no menos transitado es reseñar el vuelco político que experimentaron varios universitarios en los años sesenta y setenta. Cambio que podía ir desde una reconsideración del movimiento peronista hasta a una plena identificación con él, en un contexto político local e internacional muy distinto a las décadas del cuarenta y cincuenta. En este marco, la peronización de estudiantes, docentes e intelectuales es señalada con distinto grado de detenimiento en producciones académicas que indagan experiencias de la historia reciente de nuestro país a partir de distintas perspectivas disciplinares. Nombrar todo el corpus bibliográfico sería inabarcable, pero un listado podría ir desde los clásicos trabajos de Oscar Terán (1991), Silvia Sigal (1991), Beatriz Sarlo (2000) y Carlos Altamirano (2001) sobre la historia de las ideas y el campo intelectual, hasta otros más dedicados a la historia de las universidades y el movimiento estudiantil ${ }^{1}$. A estos también podría sumarse un conjunto de producciones que intentaron brindar un panorama da la peronización de universitarios a través de diagnósticos generales o el tratamiento de casos específicos ${ }^{2}$. E incluso, entre

\footnotetext{
${ }^{1}$ Entre los trabajos dedicados a la historia de la universidad podemos nombrar los de Peréz Lindo (1985), Buchbinder (2005), Recalde (2007), Toribio (2010) y Rodríguez (2015), mientras sobre el movimiento estudiantil los pertenecientes al grupo de Millán, Bonavena y Califa (2014). También pueden encontrarse referencias a la peronización en estudios sobre la historia de la sociología en nuestro país, como los de Pereyra (2007) y Rubinich (2007).

2 Los trabajos de Ramírez (1999), Barletta (2001, 2002) y Barletta y Tortti (2002) intentan bosquejar un panorama general sobre la peronización. En cambio, investigaciones como los de Barletta y Lenci (2001), Reta (2010), Moscona (2010), Dip (2013, 2016), Recalde (2016) y Friedemann (2017) se enfocan en experiencias político-culturales vinculadas a dicho proceso: agrupaciones estudiantiles como el Frente Estudiantil Nacional, núcleos intelectuales como las Cátedras Nacionales y publicaciones como las revistas Antropología 3er. Mundo y Envido.
}

* Licenciado en Sociología y Doctor en Historia por la Facultad de Humanidades y Ciencias de la Educación de la Universidad Nacional de La Plata. Becario Postdoctoral del Consejo Nacional de Investigaciones Científicas y Técnicas (CONICET). nicolasdip88@gmail.com 
los autores de estos últimos trabajos, pueden encontrarse a varios protagonistas directos de la experiencia histórica en cuestión, como los de Adriana Puiggrós (1991), Guillermo Gutiérrez (2009), José Pablo Feinmann (2010, 2011), Horacio González (2011), Roberto Grabois (2014) y Alcira Argumedo (2015).

Este campo bibliográfico de temáticas y marcos analíticos diversos por lo general toma como referencia a la Universidad de Buenos Aires (UBA). A su vez, concibe a los años sesenta y setenta como un entramado de articulaciones conflictivas entre la modernización cultural, los proyectos de renovación de las casas de estudio y la politización-radicalización de varios actores vinculados al sistema de educación superior. Desde este lugar, ha generado valiosos elementos empíricos y analíticos, los cuales permiten en la actualidad indagar la relación entre peronismo y universidad con mayor detenimiento, sin desconocer las múltiples tensiones entre el contexto político, el escenario cultural y el ámbito académico de ese turbulento período de la historia reciente de nuestro país.

A pesar de los avances en la bibliografía existente y de que la mayoría de los estudios hacen referencia a la UBA, todavía resta un examen sistemático del proceso de peronización porteña en lo que concierne a dos dimensiones: el plano organizativo y los discursos sobre la cuestión universitaria. En relación a la primera, falta indagar aún más en la extensión y las características específicas de dicha experiencia, teniendo en consideración los diversos escenarios político-académicos del período estudiado y las articulaciones entabladas por una multiplicidad de actores, que incluyen desde agrupaciones estudiantiles, docentes, profesionales e intelectuales hasta revistas y publicaciones a ellos asociados.

En esta primera dimensión, se enmarcan los trabajos que realizaron Juan Sebastián Califa y Nicolás Dip para el presente dossier. El primero ha analizado en su tesis doctoral (2014) la politización del movimiento estudiantil porteño en el período 1955-1966 y en su artículo retoma estos aportes para indagar el itinerario seguido por el Frente Estudiantil Nacional (FEN), una organización fundada por sectores de izquierda y reformistas luego del golpe de Estado de Juan Carlos Onganía. El derrotero seguido por este sector lo lleva a cuestionar la existencia de un proceso extendido de peronización en el movimiento estudiantil en los años sesenta y a sostener que antes de 1973 el peronismo nunca llegó a convertirse en una fuerza de peso en la UBA.

El artículo de Dip, por su parte, se enmarca en su reciente tesis doctoral (2017) dedicada al estudio de la peronización de estudiantes, docentes e intelectuales porteños entre 1966 y 1974. De esta manera, reconstruye los nuevos grupos universitarios peronistas que surgieron en la UBA luego de la intervención de Onganía, pero prestando atención a la trayectoria previa de sus principales dirigentes y militantes. Su principal aporte es el llamado a dejar de concebir de manera abstracta y general los procesos de politización y peronización con relatos que establecen recorridos lineales e ineluctables. A su entender, sería más adecuado hablar de estilos concretos de peronización, los cuales involucran trayectos que no son lineales, como diversos actores, discursos y coyunturas político-académicas. 
La otra dimensión sobre la peronización porteña que no ha sido suficientemente abordada en los estudios existentes es la vinculada al plano discurso. Todavía resta ahondar en el conjunto de relatos que pusieron en debate el perfil de las casas de estudio y su relación con la sociedad, el movimiento estudiantil y los intelectuales, considerando las diversas trayectorias de los grupos universitarios peronizados e incluso sus divergencias a la hora de entender su "pasaje" al peronismo 3 . Los trabajos de Sergio Friedemann y Juan Luis Besoky apuntan a esta cuestión. El primero retoma los aportes de su tesis doctoral (2015), dedicada a estudiar el proyecto de reforma universitaria que la izquierda peronista intentó institucionalizar con la designación de Rodolfo Puiggrós como interventor de la UBA en 1973. Para contribuir al presente dossier, aborda cómo los propios actores de la época utilizaron y dotaron de diferentes sentidos a las categorías de "nacionalización” y "peronización”. De esta manera, analiza el discurso de la Cátedras Nacionales de la Facultad de Filosofía y Letras junto a los posicionamientos de importantes referentes de la izquierda peronista de esos años, como John William Cooke, Juan José Hernández Arregui, Arturo Jauretche, Puiggrós e incluso el propio Perón.

Por otra parte, Besoky recopila varios análisis efectuados en su tesis doctoral (2016), abocada a investigar el surgimiento y desarrollo de la derecha peronista entre 1943 y 1974. En su artículo, profundiza un camino emprendido por Inés Izaguirre (2011) y se aboca al estudio de los 100 días de gestión de Alberto Ottalagano como interventor de la UBA, bajo el gobierno de Isabel Perón. Su trabajo se destaca por resaltar que la peronización no sólo involucró a sectores de izquierda en los años sesenta y setenta, a la vez que otorga varios elementos para pensar cómo era entendida la cuestión universitaria desde la derecha peronista.

Los cuatro artículos reseñados anteriormente se centran en la UBA. Sin embargo, el presente dossier a pesar de reconocer que todavía resta profundizar el conocimiento sobre el ámbito porteño, no prescinde de una problemática que aqueja a este campo de estudio. Dicha dificultad reside en que muchas veces las lecturas sobre la historia de las universidades, el movimiento estudiantil y los intelectuales son formuladas desde un enfoque "porteño-céntrico". Por esta razón, algunos trabajos han focalizado sus pesquisas en otros lugares y regiones, como los de Claudio Suasnábar (2004) en el caso de La Plata y Gastón Gil (2010) en Mar del Plata. Teniendo en cuenta este panorama, el quinto y último estudio del dossier escrito por Mariano Millán problematiza la cuestión de la peronización en Corrientes y Resistencia entre 1966 y $1973^{4}$. Su principal contribución es el llamado a pensar críticamente el "pasaje" al peronismo y las hipótesis de que la politización de los estudiantes dejó en las sombras los debates netamente universitarios.

3 Para Sarlo (2000: 91), la cuestión universitaria tiene una faz académica y una ligada a posicionamientos políticos, dado que implica discutir el perfil de la universidad, pero también su relación con la sociedad, la cultura, la ciencia, los intelectuales, los estudiantes, entre otros.

4 En su tesis doctoral (2013), el autor ya había alertado sobre la necesidad de profundizar los trabajos regionales. En la misma, aparte de trabajar los casos de Corrientes y Resistencia, trata los de Rosario, Córdoba y Tucumán. 
El presente dossier realizado especialmente para la revista Folia Histórica del Nordeste por docentes-investigadores de la UBA y la UNLP, esperan generar aportes empíricos y analíticos para profundizar el análisis de la peronización, a partir de perspectivas y cuestiones diversas. Por eso, sus cinco artículos aspiran a ser disparadores de nuevos interrogantes y discusiones sobre el tema tratado, al considerar un conjunto heterogéneo de actores estudiantiles, docentes e intelectuales y volver alertar sobre la complejidad de una experiencia político-universitaria sobre la cual resta mucho por indagar.

\section{Referencias bibliográficas}

Altamirano, C. 2001. Peronismo y cultura de izquierda, Bs. As., Temas Grupo Editorial. Argumedo, A. 2015. "Roberto Carri". En: Carri, R., Roberto Carri: obras completas, Bs. As., Biblioteca Nacional, Tomo I.

Barletta, A. M. 2010. "Peronización de los universitarios (1966-1973). Elementos para rastrear la constitución de una política universitaria peronista". En: Pensamiento Universitario, $\mathrm{N}^{\circ}$ 9, UNQUI.

Barletta, A. M. 2002. "Una izquierda universitaria peronista. Entre la demanda académica y la demanda política (1968-1973)". En: Prismas, No 6, UNQUI.

Barletta, A. M., y Lenci, M. L. 2001. "Politización de las ciencias sociales en Argentina. El caso de la revista Antropología 3er. Mundo". En: Sociohistórica, № 8, FaHCE, UNLP.

Barletta, A. M., y Tortti, M. C. 2002. "Desperonización y peronización en la universidad en los comienzos de la partidización de la vida universitaria". En: Krotsch, P. (comp.), La universidad cautiva. Legados, marcas y horizontes, La Plata, Al Margen. Besoky, J. L. 2016. La derecha peronista. Prácticas políticas y representaciones (1943-1976), Tesis Doctoral, FaHCE, UNLP.

Bonavena, P. 2014. "Los estudiantes universitarios peronista. Del golpe de Onganía a los 'azos' del '69". En: V Jornadas de estudio y reflexión sobre el movimiento estudiantil argentino y latinoamericano.

Buchbinder, P. 2005. Historia de las universidades argentinas, Bs. As., Sudamericana.

Califa, J. S. 2014. Reforma y revolución. La radicalización política del movimiento estudiantil de la UBA 1943-1966, CABA, Eudeba.

Dip, N. 2013. "El peronismo universitario en un mundo de tensiones. Una aproximación al itinerario de las organizaciones de estudiantes y docentes peronistas de los años sesenta a través del estudio del proyecto de Universidad Nacional-Popular propuesto en la revista Envido". En: Nuevo Mundo Mundos Nuevos.

Dip, N. 2016. "En busca de un relato para la universidad. Reminiscencias reformistas y peronistas en Antropología 3er. Mundo". En: E L@tina. Revista Electrónica de Estudios Latinoamericanos. 
Dip, N. 2017. Libros y alpargatas. Las tramas discursivas y organizativas del proceso de peronización de estudiantes, docentes e intelectuales de la Universidad de Buenos Aires 1966-1974, FaHCE, UNLP, Tesis de Doctorado.

Feinmann, J. P. 2010. Peronismo. Filosofía política de una persistencia argentina, Bs. As., Planeta, Tomo I.

Feinmann, J. P. 2011. Peronismo. Filosofía política de una persistencia argentina, Bs. As., Planeta, Tomo II.

Friedemann, S. 2017. "De las Cátedras Nacionales (1967-1971) a la Universidad Nacional y Popular de Buenos Aires (1973-1974). Experiencias configuradoras de institucionalidad universitaria". En: Sociohistórica, en prensa.

Friedemann, S. 2015. La Universidad Nacional y Popular de Buenos Aires (1973-1974). Una reforma universitaria inconclusa, FSOC, UBA, Tesis de Doctorado.

Gil, G. 2010. Universidad y utopía. Ciencias sociales y militancia en la Argentina de los 60 y 70 , Mar del Plata, EUDEM.

González, H. 2011. "Envido, un frente intelectual en el lodo del lenguaje político". En: Envido. Revista de politica y ciencias sociales, Bs. As., edición facsimilar de la Biblioteca Nacional, Tomo I.

Grabois, R. 2014. Memorias de Roberto Pajarito Grabois: de Alfredo Palacios a Juan Perón (1955-1974), C.A.B.A., Corregidor.

Gutiérrez, G. 2009. “Antropología 3er Mundo. Cuatro década, algunas reflexiones sobre el contexto de origen”. En: Antropología 3er. Mundo, Bs. As., edición facsimilar de la Editorial de la Facultad de Filosofía y Letras.

Izaguirre, I. 2011. "La Universidad y el Estado terrorista. La Misión Ivanissevich". En: Conflicto Social, No 5, 2011.

Millán, M. (comp.). 2014. Universidad, politica y movimiento estudiantil en Argentina: entre la Revolución Libertadora y la democracia del '83, Bs. As., Final Abierto.

Millán, M., 2016. La Juventud Universitaria Peronista en las memorias de la militancia estudiantil reformista y marxista de la UBA, 1973 - 1976. Historia, Voces y Memoria, (10), pp.49-63.

Millán, M. 2013. Entre la universidad y la política. Los movimientos estudiantiles de Corrientes y Resistencia, Rosario, Córdoba y Tucumán durante la Rev. Argentina (1966-1973), Tesis de Doctorado, FSOC., UBA.

Moscona, G. 2010. Peronismo e intelectuales: la experiencia de las Cátedras Nacionales en la UBA en el periodo 1967-1974, Tesis de Maestría, FSOC, UBA.

Pereyra, D. 2007. "Cincuenta años de la Carrera de Sociología de la UBA. Algunas notas contra-celebratorias para repensar la historia de la Sociología en Argentina”. En: Revista Argentina de Sociología, Vol. 9, Bs. As.

Pérez Lindo, A. 1985. Universidad, politica y sociedad, Bs. As., Eudeba.

Puiggrós, A. 1991. Democracia y autoritarismo en la pedagogía argentina y latinoamericana, Bs. As., Galerna.

Ramírez, A. J. 1999. "Radicalización y peronización de los estudiantes universitarios. El caso de la Universidad de La Plata". En: Cuadernos del CISH, № 5.

Recalde, A. e I. 2007. Universidad y liberación Nacional, Bs. As., Nuevos Tiempos. 
Recalde, A. 2016. Intelectuales, peronismo y universidad, Bs. As., Punto de Encuentro.

Reta, M. A. 2010. El proceso de peronización dentro del movimiento universitario en los años sesenta en la Argentina. El caso del Frente Estudiantil Nacional, Tesis de Maestría, Facultad Cs. Sc., UBA.

Rodríguez, L. G. 2015. Universidad, Peronismo y Dictadura 1973-1983, C.A.B.A, Prometeo.

Rubinich, L. 2007. "La modernización cultural y la irrupción de la sociología". En: James, D. (comp.), Violencia, proscripción y autoritarismo (1944-1976), Bs. As., Sudamericana.

Sarlo, B. 2000. La batalla de las ideas, Bs. As., Ariel.

Sigal, S. 1991. Intelectuales y poder en la década del sesenta, Bs. As., Puntosur.

Suasnábar, C. 2004. Universidad e intelectuales. Educación y politica en la Argentina (1955-1976), Bs. As., Manantial.

Terán, O. 1991. Nuestros años sesenta, Bs. As., Puntosur.

Toribio, D. 2010. "La expansión de la Educación Superior en contextos de crisis sociales y políticas". En: La universidad en la Argentina: miradas sobre su evolución y perspectivas, UNLA. 